\title{
Flavonoid-rich berry-extract treatment influences expression of genes in the copper-uptake pathway in human intestinal Caco-2 cells
}

\author{
F. Alzaid, A. Robotham, K. Pourvali, P. A. Sharp, V. R. Preedy and H. Wiseman \\ King's College London, Nutritional Sciences Division, Franklin-Wilkins Building, 150 Stamford Street, \\ London SE1 9NH, UK
}

Berries are a rich dietary source of bioactive polyphenols, including flavonoids, such as anthocyanins ${ }^{(1)}$. Dietary flavonoids are known to chelate $\mathrm{Cu}^{2+}$ and are known to alter the uptake of metal ions in human intestinal Caco-2 cells ${ }^{(2,3)}$. However, little is known about the effects of dietary polyphenols on the expression of genes involved in the Cu-uptake pathway in the human intestine. The present study investigated the influence of a flavonoid-rich berry-extract on the expression of the following genes which co-ordinate the intestinal uptake of $\mathrm{Cu}$ : the cell surface metalloreductase (DCYTB); the $\mathrm{Cu}$ importers, divalent metal ion transporter (DMT1) and Cu transporter 1 (CTR1); the intracellular $\mathrm{Cu}$ chaperone (HAH1) and metallothionein (MT); the $\mathrm{Cu}$ transporting ATPases (ATP7A and ATP7B) ${ }^{(4)}$.

Human intestinal Caco-2 cells, cultured for $19 \mathrm{~d}$, were treated for $16 \mathrm{~h}$ with a flavonoid-rich berry-extract (OptiBerry; InterHealth Nutraceuticals, Benicia, CA, USA) at a final concentration of $0.125 \%$ (w/v). RNA was isolated for quantitative RT-PCR. All gene expression data were normalised to $18 \mathrm{~S}$ and GAPDH as housekeeping genes and presented as mean normalised expression ratios \pm SEM. Statistical significance was determined by Student's $t$ test with significance indicated at $P \leq 0.05(n 12)$.

Following treatment with the berry extract there were significant decreases in DMT1 $(0.73 \pm 0.08, P<0.04)$, CTR $1(0.67 \pm 0.06$, $P<0.01)$, HAH1 $(0.82 \pm 0.06, P<0.03)$ and ATP7B $(0.72 \pm 0.05, P<0.001)$ mRNA expression (Fig. 1$)$. The mRNA expression of the other genes did not change significantly in response to the berry-extract treatment.

These results indicate that berry flavonoids influence the expression of components of the Cu-uptake pathway. Studies are in progress to investigate the biological relevance of the observed effects in relation to berry consumption and the bioavailability of dietary $\mathrm{Cu}$.
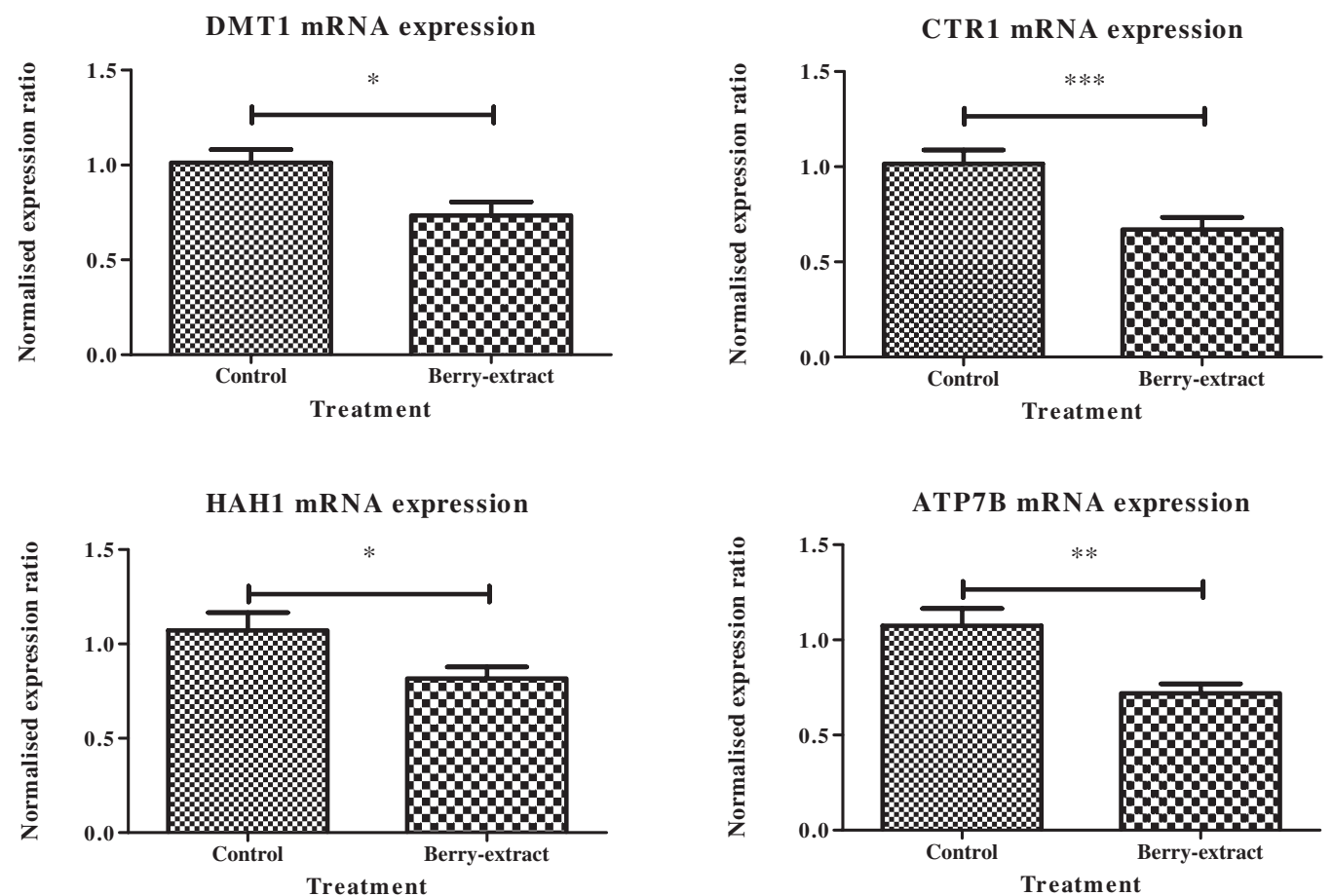

Fig. 1. Effects of berry-extract treatment on the mRNA expression of DMT1, CTR1, HAH1 and ATP7B involved in the Cu-uptake pathway in intestinal Caco-2 cells. Data expressed as mean (SEM), $n 12 ; * P \leq 0.05, * * P \leq 0.01, * * * P \leq 0.001$.

1. Zafra-Stone S, Yasmin T, Bagchi M et al. (2007) Berry anthocyanins as novel antioxidants in human health and disease prevention. Mol Nutr Food Res 51, 675-683.

2. Lekka Ch E, Ren J, Meng S et al. (2009) Structural, electronic, and optical properties of representative Cu-flavonoid complexes. J Phys Chem B 113(18), 6478-6483.

3. Kuo SM, Leavitt PS \& Lin CP (1998) Dietary flavonoids interact with trace metals and affect metallothionein level in human intestinal cells. Biol Trace Elem Res 62(3),135-153.

4. Lonnerdal B (2008) Intestinal regulation of copper homeostasis: a developmental perspective. Am J Clin Nutr 88(3), 846S-850S 